\title{
Big data y open data en la administración turística: acceso y reutilización de información*
}

Felio José Bauzá Martorell

DOI: https://doi.org/10.47623/ivap-rvap.108.2017.01

\begin{abstract}
Sumario: I. La Administración turística ante la transformación digital del sector. I.1. La nueva Administración turística. I.2. Las plataformas colaborativas. I.3. La revolución de los datos turísticos. -II. Acceso a los datos turísticos. II.1. Acceso a los datos que obran en poder de la Administración turística. II.1.A. Información turística pública. II.1.B. Límites al derecho de acceso. II.2. Acceso por parte de la Administración turística a los datos que obran en la red. II.2.A. Datos facilitados por su titular. II.2.B. Datos facilitados por un tercero. II.2.C. Datos obtenidos por la Administración en el ejercicio de sus funciones. II.3. Seguridad y garantía de la privacidad.-III. Reutilización de datos turísticos. III.1. Régimen jurídico. III.2. Proyecto Aporta. III.3. Ciudades inteligentes y datos abiertos. -IV. Conclusiones. -V. Bibliografía.
\end{abstract}

\section{La Administración turística ante la transformación digital del sector}

\section{I.1. La nueva Administración turística}

En el contexto de una general transformación digital de la sociedad y la economía, que abarca todos los segmentos sociales y los sectores económicos (educación, salud, energía, transporte...) quizás sea el turismo aquel que ha experimentado una variación más intensa con ocasión de los medios técnicos.

La nueva dimensión de la contratación turística(1) - a distancia por un lado, y con la intervención de agentes mediadores (agencias de viajes en

\footnotetext{
* Artículo redactado en el marco del proyecto de investigación «Big data, cloud computing y otros nuevos retos jurídicos planteados por las tecnologías emergentes, en particular, su incidencia en el sector turístico" (DER2015-63595-R, Universidad de las Islas Baleares, MINECO y Fondos FEDER).
}

(1) Sobre contratos turísticos, vid. RAMALLO MIÑÁN, E. P.: Manual básico del derecho turístico. Tecnos. Madrid, 2013. Págs. 53 a 65. 
línea - OTAs(2), centrales electrónicas de reservas turísticas) que operan desde cualquier Estado a través de plataformas digitales (3), por otro- ha supuesto una forma radicalmente distinta a la convencional en la relación jurídica entre los usuarios y los prestadores de servicios turísticos, al tiempo que invariablemente ha obligado a la Administración a modular y adaptar su intervención en el sector.

En este sentido hasta fechas recientes la Administración desplegaba su función de policía administrativa a través del control previo y la técnica autorizatoria (licencias sectoriales previas), y el control a posteriori mediante la inspección turística. En cambio la proliferación de la nueva forma de contratación turística, una vez sustituida la licencia previa por la declaración responsable (4), obliga a la Administración a hacer uso de los mismos medios técnicos con que operan los agentes turísticos y analizar si se respetan los derechos de los usuarios (principalmente su libertad de opinión en los comentarios vertidos en las redes sociales) o si por el contrario existen extralimitaciones (penalizaciones que puedan imponer los titulares de los medios técnicos ante opiniones negativas vertidas por usuarios, fraude en opiniones negativas falsas que persiguen desacreditar a competidores $u$ obtener provecho propio en forma de descuentos o alojamientos gratuitos) (5).

\section{I.2. Las plataformas colaborativas}

Nadie duda que en estos tiempos la economía colaborativa goza de un auge sin precedentes, y que en ese contexto cobran importancia las plataformas que le sirven de soporte y a través de las cuales discurre gran cantidad de información.

Este nuevo modelo de negocio ha creado un sistema de mercado multilateral, en cuyo seno las nuevas tecnologías - a través de plataformashan multiplicado exponencialmente las posibilidades de interacción entre

(2) Acrónimo del anglicismo on line travel agencies.

(3) BAUZÁ MARTORELL, F. J.: «Hacia una legislación básica en materia de turismo. A propósito de las centrales electrónicas de reservas turísticas", en Diario La Ley. 27 de mayo de 2014.

(4) FERNÁNDEZ RODRíGUEZ, C.: Derecho administrativo del turismo. Séptima edición. Marcial Pons. Madrid, 2016. Págs. 102 a 105. Vid. también BAUZÁ MARTORELL, F. J.: «Incidencia de la Directiva de Servicios en la legislación turística. Estudio autonómico comparado». En JIMÉNEZ CABALLERO, J. L. y DE FUENTES RUIZ, P. (Coords): Turismo y desarrollo económico. Actas de las IV Jornadas de Investigación en Turismo. Facultad de Turismo y Finanzas de la Universidad de SeviIla. 2011. Págs. 339 a 355.

(5) BAUZÁ MARTORELL, F. J.: "Replanteamiento de la intervención administrativa en materia de turismo ante las nuevas tecnologías», en Actualidad Administrativa núm. 3. Marzo 2016. Págs. 61 a 75. 
grupos que tradicionalmente no tenían relación o lo hacían de manera ineficiente (6).

El éxito de las plataformas de economía colaborativa descansa en el elemento tecnológico, que incorpora motores de búsqueda, acopio y gestión de datos mediante la creación de comunidades de personas afines, sistemas de geolocalización... (7).

\section{I.3. La revolución de los datos turísticos}

Los medios técnicos y la contratación a distancia se traducen sistemáticamente en una proliferación y profusión de datos que circulan por la red sin que su control pueda ser por razones materiales exhaustivo.

En efecto a diario se transmiten por las redes sociales datos relativos a destinos, orígenes, preferencias (sol y playa, deportes, cultura, restauración...), capacidades de gasto, datos sobre comportamientos (turismo familiar, de ocio, de salas de fiestas...) que afectan a millones de usuarios. Pese a que tales datos tienen unos titulares, sin embargo son manejados por tantos interlocutores que se convierten en altamente vulnerables.

Se conoce con el anglicismo de big data el conjunto de datos cuyo tamaño supera la capacidad de búsqueda, captura, almacenamiento, gestión, análisis, transferencia, visualización, o protección legal de las herramientas convencionales (8).

En el sector del turismo esta revolución de los datos es particularmente intensa e importante. Intensa porque la estadística revela que más del $95 \%$ de los viajeros utilizan los recursos digitales en el transcurso de sus viajes, visitando una media de 19 páginas web en cada viaje (9); el canal móvil se ha convertido en un importante medio de venta en el sector, alcanzando el 12 '5\% de todas las reservas en línea(10). E importante porque en general la revolución digital tiene un impacto de 1'25 billones de

(6) MONTERO PASCUAL, J. J.: "La regulación de la economía colaborativa». En MONTERO PASCUAL, J. J. (Director): La regulación de la economía colaborativa. Airbnb, BlaBlaCar, Uber y otras plataformas. Tirant lo Blanch. Valencia, 2017. Pág. 29.

(7) ALFONSO SÁNCHEZ, R. y BURILLO SÁCNHEZ, F. J.: "La economía llamada colaborativa». En ALFONSO SÁNCHEZ, R. VALERO TORRIJOS, J. (Directores): Retos jurídicos de la economía colaborativa en el contexto digital.The Global Collection. Aranzadi Thomson Reuters. 2017. Pág. 29.

(8) AAVV.: Big data. Retos y oportunidades para el turismo. Instituto Valenciano de Tecnologías Turísticas. Valencia, 2015. Pág. 9.

(9) Fuente:The Boston Consulting Group. Citado en Fundación Orange. La transformación digital en el sector turístico.

(10) Fuente: UniMOOC. 9 tendencias tecnológicas que están transformando el turismo. 16 de junio de 2016. 
euros en las principales economías mundiales(11), y en particular porque los datos en turismo tienen un valor estratégico de primer orden en tanto que permiten predecir comportamientos futuros y adelantarse con ofertas competitivas. Adicionalmente en el turismo más que en cualquier otro ámbito el flujo de datos puede ser nacional, pero también transfronterizo, extremo que complica sobre manera las relaciones jurídicas de contratación y de impugnación en sede judicial y - por lo que aquí interesa- de control administrativo(12).

La técnica de los macro datos combina el tratamiento de un mayor volumen de información, a una velocidad superior, de una variedad de datos y de fuentes distintas, alcanzando una mayor exactitud en el tratamiento de la información.

En efecto un análisis inteligente de los datos permite detectar comportamientos y tendencias, conocer al cliente y el desarrollo del producto, optimizar procesos, atraer y fidelizar clientes, y en definitiva tomar decisiones de manera proactiva y con celeridad. Todo ello en un sector que mueve 113.690 millones de euros anuales y que constituye el $10^{\prime} 9 \%$ del PIB(13).

A mayor abundamiento esta masificación de datos turísticos se inserta en un contexto de gobierno abierto y transparencia (14), de manera que el ordenamiento jurídico obliga a publicar la información relevante de que dispongan las Administraciones Públicas, haciendo posible la reutilización de los datos mediante el uso de estándares tecnológicos y de tratamientos masivos de información.

De ahí que en consecuencia resulte obligado analizar los macro datos y los datos abiertos en el sector turístico, y en particular el acceso a los datos turísticos que obran en poder de la Administración y la reutilización de los mismos (15).

(11) Fuente: Índice de densidad digital: guiando la transformación digital. Accenture. Citado en Fundación Orange. La transformación digital en el sector turístico.

(12) Sobre la transferencia internacional de datos, vid. ABERASTURI GORRIÑO, U.: "Movimiento internacional de datos. Especial referencia a la transferencia internacional de datos sanitarios", en Revista de Administración Pública núm. 186. Madrid, septiembre-diciembre 2011. Págs. 329 a 369. BUISÁN GARCÍA, N.: "Movimiento internacional de datos», en LESMES SERRANO, C. (Coord.): $L a$ Ley de Protección de Datos. Análisis y Comentario de su Jurisprudencia. Lex Nova. Valladolid, 2008. Pág. 572. BARCELÓ, R. y PÉREZ ASINARI, M. V.: "Transferencia internacional de datos personales», en MARTíNEZ MARTÍNEZ, R. (Coord.): Protección de Datos. Comentarios al Reglamento de desarroIlo de la LOPD. Tirant lo Blanch. Valencia, 2009. Pág. 145.

(13) Fuente: Instituto Nacional de Estadística. Cuenta satélite delTurismo de España. 2016.

(14) COTINO HUESO, L.: «El derecho fundamental de acceso a la información, la transparencia de los poderes públicos y el Gobierno Abierto. Retos y oportunidades». En VALEROTORRIJOS, J. y FERNÁNDEZ SALMERÓN, M. (Coords): Régimen jurídico de la transparencia del sector público. Thomson Reuters - Aranzadi. Cizur Menor, 2014. Págs. 37 a 71.

(15) Como ejemplo reciente, directamente vinculado al sector del turismo, la Agencia Estatal de Meteorología (AEMET), ha puesto en funcionamiento en diciembre de 2016 el centro de descargas $A E M E T$ Open Data para la difusión y reutilización de sus datos meteorológicos y climatológicos, en 


\section{Acceso a los datos turísticos}

Regulado con carácter básico (16) en la Ley 19/2013, de 9 de diciembre, de Transparencia, acceso a la información pública y buen gobierno (en adelante, LTABG), el acceso a la información pública se configura como un derecho de todas las personas (art. 12 LTABG), configurado al más alto nivel en el art. 105 CE y con el alcance y límites previstos en la propia LTABG y normativa complementaria, especialmente la LOPD (17).

En el seno de la Unión Europea el acceso a los datos públicos no puede tener un ámbito meramente estatal, de ahí que las instituciones comunitarias se esfuercen en aplicar políticas de armonización que superen una eventual fragmentación del mercado(18). Tal es el caso de la Directiva 2016/2102, del Parlamento Europeo y del Consejo, de 26 de octubre de 2016, sobre la accesibilidad de los sitios web y aplicaciones para dispositivos móviles de los organismos del sector público, que concibe la accesibilidad como un conjunto de principios y técnicas que se deben respetar a la hora de diseñar, construir, mantener y actualizar los sitios web y las aplicaciones para dispositivos móviles para que sean más accesibles a los usuarios, en particular a las personas con discapacidad.

Desde el punto de vista subjetivo resulta indudable que la expresión de todas las personas es omnicomprensiva y que en consecuencia afecta tanto a las personas públicas como a las privadas, de manera que -en lo que respecta a los datos turísticos - habrá que admitir la posibilidad de que particulares accedan a los datos obrantes en poder de la Administración turística para fines comerciales o no comerciales, como también la opción que asiste a la Administración turística de interceptar los datos de usuarios y prestadores de servicios turísticos que circulan en las redes sociales, siendo este un medio idóneo para desplegar la actividad inspectora y consiguientemente la potestad sancionadora.

\footnotetext{
aplicación de la Ley 37/2007 y de acuerdo con el Esquema Nacional de Interoperabilidad en el ámbito de la Administración Electrónica. AEMET Open Data facilita la descarga de información procedente de gran cantidad de sensores y dispositivos inteligentes localizados a lo largo del territorio nacional, sobre los que permite a empresas, administraciones y ciudadanos aplicar "técnicas de procesamiento de datos masivos (big data) para detectar patrones de comportamiento ocultos».
}

(16) Disposición final octava de la LTABG.

(17) Respecto al título competencial no se olvide que el turismo en España es una materia de competencia autonómica y que en consecuencia resultará aplicable la normativa relativa a transparencia que haya sido aprobada por cada Comunidad autónoma. Sobre el reparto competencial en materia de acceso a la información pública, vid. PÉREZ MONGUIÓ, J. M. y FERNÁNDEZ RAMOS, S.: La Ley de Transparencia, acceso a la información pública y buen gobierno. Aranzadi Thomson Reuters. Cizur Menor, 2014. Págs. 50 a 71.

(18) GUICHOT REINA, E.: «El sentido, el contexto y la tramitación de la Ley de transparencia, acceso a la información pública y buen gobierno». En GUICHOT REINA, E. (Coord.): Transparencia, acceso a la información pública y buen gobierno. Tecnos. Madrid, 2014. Págs. 17 a 34. 


\section{II.1. Acceso a los datos que obran en poder de la Administración turística}

La política de datos abiertos de los poderes públicos persigue una doble finalidad: el progreso en la transparencia de la Administración y el servir de medio para la reutilización de la información del sector público.

En este punto nos referimos al ejercicio por un particular u otra Administración del derecho de acceso y no tanto a la información publicada en calidad de datos abiertos. Así, debemos admitir la existencia de portales públicos de datos abiertos en la Administración General del Estado (Iniciativa Aporta), las Comunidades autónomas (proyecto Open Data Euskadi, Datos Abiertos Gencat...) y muchas Corporaciones locales, si bien persiguen la reutilización de la información del sector público, como veremos en el epígrafe correspondiente.

\section{II.1.A. INFORMACIÓN TURÍSTICA PÚBLICA}

En materia de acceso habrá que partir de qué datos pueden ser objeto de acceso y qué limitaciones operan en el mismo. En este sentido la LTABG ciñe el acceso a la información estrictamente pública, que define en el art. 13 como aquellos contenidos o documentos, cualquiera que sea su formato o su soporte, que obren en poder de alguno de los sujetos incluidos en su ámbito de aplicación(19), y que hayan sido elaborados o adquiridos en el ejercicio de sus funciones.

(19) Según el art. 2.1 LTABG el ámbito subjetivo de aplicación comprende:

a) La Administración General del Estado, las Administraciones de las Comunidades Autónomas y de las Ciudades de Ceuta y Melilla y las entidades que integran la Administración Local.

b) Las entidades gestoras y los servicios comunes de la Seguridad Social así como las mutuas de accidentes de trabajo y enfermedades profesionales colaboradoras de la Seguridad Social.

c) Los organismos autónomos, las Agencias Estatales, las entidades públicas empresariales y las entidades de Derecho Público que, con independencia funcional o con una especial autonomía reconocida por la Ley, tengan atribuidas funciones de regulación o supervisión de carácter externo sobre un determinado sector o actividad.

d) Las entidades de Derecho Público con personalidad jurídica propia, vinculadas a cualquiera de las Administraciones Públicas o dependientes de ellas, incluidas las Universidades públicas.

e) Las corporaciones de Derecho Público, en lo relativo a sus actividades sujetas a Derecho Administrativo.

f) La Casa de su Majestad el Rey, el Congreso de los Diputados, el Senado, el Tribunal Constitucional y el Consejo General del Poder Judicial, así como el Banco de España, el Consejo de Estado, el Defensor del Pueblo, el Tribunal de Cuentas, el Consejo Económico y Social y las instituciones autonómicas análogas, en relación con sus actividades sujetas a Derecho Administrativo.

g) Las sociedades mercantiles en cuyo capital social la participación, directa o indirecta, de las entidades previstas en este artículo sea superior al 50 por 100. 
Este concepto legal de información pública conduce a que la Administración turística deba permitir el acceso a los ciudadanos de todos aquellos datos que obren en contenidos o documentos elaborados o adquiridos en el ejercicio de sus funciones, extremo de gran amplitud, que obliga a limitar con ocasión de otros bienes jurídicos más dignos de protección.

\section{II.1.B. LÍMITES AL DERECHO DE ACCESO}

Sin perjuicio de la protección de datos (art. 15 LTABG), el art. 14 enumera los límites al derecho de acceso que -en lo que a información turística se refiere- son de interés la prevención, investigación y sanción de ilícitos administrativos (apartado e), así como las funciones administrativas de vigilancia, inspección y control (apartado g).

Otra cosa es que la realidad, como veremos con mayor detenimiento, discurra por un camino que relativiza estos límites al derecho de acceso. Así, el Informe Cannataci del Consejo de Derechos Humanos de Naciones Unidas pone de relieve que a día de hoy las empresas con fines comerciales (con implantación transfronteriza) gestionan un mayor volumen de datos que los propios gobiernos (20) y que en consecuencia la captura de datos se convierte en un importantísimo activo empresarial para disponer de un mapa de comportamiento de los consumidores(21). Para el sector turístico esta información es clave para predecir tendencias y anticiparse a la demanda formulando ofertas, teniendo en cuenta que la planificación del consumo de servicios turísticos se realiza con una antelación al menos de un año.

h) Las fundaciones del sector público previstas en la legislación en materia de fundaciones.

i) Las asociaciones constituidas por las Administraciones, organismos y entidades previstos en este artículo. Se incluyen los órganos de cooperación previstos en el artículo 5 de la Ley 30/1992, de 26 de noviembre, de Régimen Jurídico de las Administraciones Públicas y del Procedimiento Administrativo Común, en la medida en que, por su peculiar naturaleza y por carecer de una estructura administrativa propia, le resulten aplicables las disposiciones de este título. En estos casos, el cumplimiento de las obligaciones derivadas de la presente Ley serán Ilevadas a cabo por la Administración que ostente la Secretaría del órgano de cooperación.

(20) CANNATACI, J. A.: Report of the Special Rapporteur on the right to privacy. Human Rigths Council. United Nations. 2016.

(21) Los medios de comunicación confirman la importancia que las empresas confieren a la gestión de datos: en su edición de 5 de agosto de 2016 la prensa española publica que Mercadona invierte 21 millones de euros en la construcción de un centro de datos en León; Telefónica inauguró en 2013 un centro de datos en el Parque Científico y Tecnológico de Alcalá de Henares, con 23 salas tecnológicas que ofrecen servicios de computación en la nube y de procesamiento masivo para empresas. 


\section{II.2. Acceso por parte de la Administración turística a los datos que obran en la red}

Como venimos diciendo, los medios técnicos en el sector turístico por un lado han reducido la actividad de mediación por cuanto permiten relacionar directamente al usuario con el prestador de servicios turísticos, y, por otro, intensifican esta actividad de mediación, toda vez que hacen posible que portales de internet en cualquier lugar del mundo se conviertan en mediadores (22).

En cualquier caso, ya sea porque el prestador de servicios se anuncia en la red (el caso del propietario de viviendas turísticas vacacionales que ofrece un inmueble de su propiedad, a cambio de un precio, en un portal como airbnb), o porque un portal web intercepta el anuncio de un particular y lo incorpora a su catálogo de servicios, lo cierto y verdad es que millones de datos de usuarios y prestadores de servicios turísticos circulan por la red sin apenas control.

Siendo así que la realidad del sector turístico deriva hacia el mundo digital, la intervención administrativa no puede quedarse anclada en las visitas de inspección y el requerimiento de documentación, porque en ese caso no alcanza la plenitud de la relación jurídico-administrativa. El análisis de las redes se convierte en imprescindible para asegurar el cumplimiento de la normativa turística y el análisis de macro datos desde luego permite realizar comprobaciones masivas y automatizadas de ese cumplimiento o incumplimiento (fraude). En caso contrario nos encontramos con la paradoja de que la normativa aplicable no se exige a un buen número de obligados, porque sencillamente no existen para la Administración turística, porque no hay constancia de su intervención en el mercado como operadores turísticos, y el control sobre los mismos se da exclusivamente en caso de una eventual denuncia(23).

En este sentido la actividad inspectora de la Administración turística puede vincular datos obtenidos en la red con sus propias bases de datos y confirmar en un tiempo muy reducido si tiene constancia de que un particular comercializa su vivienda y en consecuencia puede o debe ser objeto de control administrativo, de que un establecimiento de alojamiento hotelero comercializa más plazas de las que tiene declaradas, o presta servicios inferiores a los que se encuentra obligado por ley.

(22) BAUZÁ MARTORELL, F. J.: «Transformaciones del derecho público del turismo con ocasión de las nuevas tecnologías". En MARTíNEZ NADAL, A. (Coord.): Turismo y nuevas tecnologías. Thomson Reuters - Aranzadi. Cizur Menor, 2016. Págs. 127 a 156.

(23) REBOLLO PUIG, M.: «La actividad inspectora». En DÍEZ SÁNCHEZ, J. J. (Coord.): La función inspectora. Actas del VIII Congreso de la Asociación Española de profesores de Derecho Administrativo. Alicante, 8 y 9 de febrero de 2013. Págs. 55 a 116. 
La pregunta obligada en este punto consiste en si la Administración turística puede aprehender tales datos, y la respuesta será distinta en función de si accede a tales datos directamente del particular o a través del mediador.

\section{II.2.A. DATOS FACILITADOS POR SU TITULAR}

La Administración turística hace uso de los medios técnicos -internet, blogs, foros... - para verificar, por ejemplo, que una vivienda turística vacacional se ha dado de alta en el registro correspondiente y en consecuencia cumple los requisitos legalmente exigidos (higiene y limpieza, cambio de sábanas y toallas, en su caso cobro y pago del impuesto de estancias turísticas, comunicación de datos a la Dirección General de la Policía...).

El acceso directo a tales datos publicados por su propio titular permite a la Administración sin ningún obstáculo desplegar su actividad inspectora $y$, en su caso, iniciar un procedimiento sancionador. El consentimiento del titular de tales datos puede calificarse de inequívoco en los términos del art. 6 LOPD, porque él mismo ha dado publicidad a tales datos de manera consciente y al objeto de entablar una relación comercial (y jurídica).

\section{II.2.B. DATOS FACILITADOS POR UN TERCERO}

Si la Administración turística encuentra circulando por las redes información y datos de un titular que han sido recabados y publicados por un tercero, resulta obligado plantearse si puede hacer uso de tales datos en su actividad inspectora o si por el contrario existe algún género de limitación.

Nuevamente en este punto debemos plantear dos hipótesis alternativas, que se distinguen en función de cómo el tercero ha accedido a tales datos.

En este sentido si los datos captados por el tercero (y en última instancia por la Administración) son los mismos datos que su titular ha hecho públicos en las redes, en ese caso habrá que colegir que este último los hizo, en su momento, públicos y que en consecuencia no puede escudarse en que los haya difundido un tercero. Nos referimos a la información que un mediador turístico (atrapalo, kayak, trivago...) publicite en su página web y que ha incorporado de un anuncio particular realizado por el titular de los datos, o incluso la información obtenida y comercializada por una empresa info mediaria.

En ese caso de nuevo existe un consentimiento inequívoco del titular de los datos a su publicidad, de modo que nada obsta a que - una vez 
despojados de reserva o privacidad por su propio titular - sean difundidos directamente por él o por un tercero, máxime cuando él mismo se beneficia de la difusión y publicidad que el tercero le dé a su anuncio. La información se difunde precisamente para que sea conocida por un número ilimitado de personas.

Por el contrario si el tercero difunde datos cuyo titular no ha renunciado a su privacidad, en ese caso la Administración sólo podría hacer acopio de los mismos si accediera a los mismos en ejercicio de sus funciones, por ejemplo, la actividad inspectora.

No puede dejar de advertirse con VALERO TORRIJOS que los macro datos en la Administración deben acompañarse de algún género de garantías, toda vez que los datos interceptados con este tratamiento masivo y automatizado tiene un origen totalmente ajeno a la intervención administrativa, de manera que debería procedimentalizarse esta captación de datos (24).

No obstante, no es menos cierto que la actividad inspectora no forma parte del procedimiento administrativo sancionador, tratándose exclusivamente de una actividad administrativa de comprobación, cuyas actas sirven de denuncia que en todo caso excita el procedimiento sancionador, pero que - al ser previo al inicio del mismo- no se integra en el expediente e incluso el denunciado no tiene derecho a conocer su contenido(25).

En efecto el art. 53.1.a de la Ley 39/2015, de 1 de octubre, de Procedimiento Administrativo Común, reconoce el derecho de los interesados a conocer el estado de tramitación de los procedimientos en los que tengan la condición de interesado, y al acceso y a la obtención de copias de los documentos obrantes en el expediente. Sin embargo, insistimos, al no formar parte la actividad inspectora del procedimiento, el particular no puede conocer de qué manera la Administración turística hizo acopio de tales datos, si de forma lícita o ilícita.

\section{II.2.C. DATOS OBTENIDOS POR LA AdMINISTRACIÓN EN EL EJERCICIO DE SUS FUNCIONES}

El art. 6 LOPD exime del consentimiento inequívoco del titular de aquellos datos que se recojan para el ejercicio de las funciones propias de las Administraciones Públicas en el ámbito de sus competencias.

(24) VALERO TORRIJOS, J.: «El big data en las Administraciones Públicas: el difícil equilibrio entre eficacia de la actividad administrativa y garantía de los derechos de los ciudadanos». En AAVV. Big data. Retos y oportunidades. Actas del IX Congreso Internacional Internet, Derecho y Política. Universitat Oberta de Catalunya. Barcelona, 25 y 26 de junio de 2013. Pág. 133.

(25) Esta problemática se aborda in extenso en BAUZÁ MARTORELL, F. J.: «Habeas denuncia. Identidad del denunciante en el procedimiento sancionador", en Revista General de Derecho Administrativo núm. 40. lustel. Octubre de 2015. 
Esta habilitación legal resulta predicable por el mero hecho de que la Administración acceda a los datos en el ejercicio de cualquier función que tenga legalmente atribuida, independientemente de que los datos hayan sido puestos en circulación por su titular o por un tercero, autorizado o no. Por el mero hecho de que la Administración turística investigue el cumplimiento de la normativa turística en el ejercicio de su actividad inspectora, sólo por ello se encuentra autorizada para acceder a datos personales.

\section{II.3. Seguridad y garantía de la privacidad}

Tratándose de datos turísticos, cuyo acceso y reutilización tienen una importante implicación económica, la ciberseguridad deviene indispensable para la prevención de ataques de terceros (26). No olvidemos que en el contexto de los macro datos cualquier operador de datos puede tener relaciones con terceros países que carezcan del mismo nivel de protección de datos y en consecuencia someter la información a indudables amenazas.

A pesar de que hayamos adelantado la protección de la privacidad en el entorno digital, conviene tener presente que con carácter general el acceso a los datos constituye una cesión a efectos de la LOPD, generándose un inevitable conflicto entre la transparencia y la privacidad, sin que resulte claro en ocasiones situar la frontera entre una y otra(27).

Por otro lado la información y la contratación turísticas mediante medios técnicos dejan un rastro o huella digital del particular, que puede ser utilizado por terceros con fines comerciales o no comerciales.

A día de hoy el usuario de servicios turísticos va confeccionando una traza personalizada de sus preferencias y experiencias: visita páginas web, busca en redes las opiniones de otros usuarios, vierte las suyas propias, planifica su itinerario o viaje combinado, reserva y paga transportes, alojamiento, entradas a espectáculos de ocio... Los medios técnicos permiten apreciar una identidad digital del usuario en permanente construcción a medida que compra un billete de avión, pulsa un me gusta sobre determinados contenidos de Facebook, comparte una fotografía, visita una tienda on line...

(26) MASSENO, M. D.: «Personal data circulation from the EU to USA and now what for the American Tourism Industry with business in Europe?" Conferencia pronunciada en la 23rd International Tourism Safety Conference. Las Vegas, Nevada, del 10 al 13 de abril de 2016.

(27) MARTÍNEZ MARTÍNEZ, R.: «De la opacidad a la casa de cristal. El conflicto entre privacidad y transparencia". En VALERO TORRIJOS, J. y FERNÁNDEZ SALMERÓN, M. (Coords.): Régimen jurídico de la transparencia del sector público. Del derecho de acceso a la reutilización de la información. Thomson Reuters Aranzadi. Cizur Menor, 2015. Págs. 241 a 280. 
Con carácter general los medios técnicos han elaborado una nueva clase de datos personales muy distintos a los convencionales: del análisis de conversaciones en redes sociales se extraen datos sobre pautas de consumo, solvencia económica, necesidades y preferencias; se instalan sensores en automóviles para conocer su ubicación y predecir una masificación; muchas ciudades disponen de tarjetas digitales de transporte que permiten optimizar las rutas haciendo uso de datos encriptados en la ciudad de Madrid o borrando los datos cada cuarenta y ocho horas en París.

La política de cookies es especialmente intensa en materia de turismo, de manera que la consulta reiterada de una oferta va encareciendo su precio; o los beacons, que hacen posible con base en el geo-posicionamiento una avalancha de información de establecimientos cercanos en los dispositivos móviles.

Con carácter inicial los datos obtenidos no tienen por qué asociarse a una persona concreta; sin embargo su tratamiento sí permite vincularlos y hasta identificar a su titular, de manera que deviene inexcusable la aplicación del régimen jurídico de protección de datos personales.

No obstante, los datos que pueden obtenerse a partir de esta huella digital no se hallan amparados por un consentimiento de su titular en los términos del art. 6 LOPD, de manera que su utilización por terceros integra el tipo infractor del art. 44.3.b y c LOPD en el sentido de tratar y ceder datos personales sin recabar el consentimiento de su titular, constituyendo una infracción grave(28).

A mayor abundamiento, y ya conectando el acceso con la reutilización, la información que inicialmente se ha generado en un determinado contexto puede ser utilizada para fines distintos a aquellos para los que los datos fueron recabados, con la participación de actores que pueden moverse por intereses crematísticos y no por el interés general.

En este punto se aprecia una divergencia entre el régimen jurídico - que se sigue dictando sobre la base del consentimiento- y la imparable realidad, que accede a los datos para darles un uso distinto, a veces comercializando la información obtenida con base en el derecho de acceso. Tal es el caso de la Sentencia delTribunal de Justicia de la Unión Europea de 16 de octubre de 2016 (asunto C-582/2014), que califica como dato personal para el gestor del sitio web, la dirección de protocolo de Internet dinámica de un usuario, cuando dicho gestor (en el caso, público) dispone de medios legales que le permitan identificar al usuario gracias a la información suplementaria de que dispone el proveedor de acceso a Internet del usuario.

(28) FERNÁNDEZ SALMERÓN, M. y VALERO TORRIJOS, J.: "Las infracciones de las Administraciones Públicas». En TRONCOSO, A. (Dir.): Comentarios a la Ley Orgánica de Protección de Datos de Carácter Personal.Thomson Reuters - Aranzadi. Cizur Menor, 2010. 


\section{Reutilización de datos turísticos}

La información de que disponen las Administraciones Públicas en el ejercicio de sus funciones (autorizaciones, control y fiscalización, seguimiento, estadísticas...) tiene un incalculable valor tanto para otros organismos públicos como para el sector privado. Estos datos públicos, combinados con otros datos públicos y privados, permiten crear y agregar valor, contribuyendo a prestar servicios públicos más eficaces y eficientes, al tiempo que contribuyen al crecimiento económico y la generación de riqueza y empleo (29).

En el caso concreto del turismo, la Administración genera gran cantidad de información de interés para el sector privado. La creación de redes de conocimiento y la gestión de esa información es un elemento clave para la competitividad del sector, al que le interesan no sólo datos estrictamente turísticos (alojamiento, oficinas de turismo, restauración...), sino también los relativos a la cultura y patrimonio, meteorología, compras, ocio, transporte, negocios, naturaleza, deportes... (30) y hasta - por qué no- políticas de simplificación administrativa(31).

\section{III.1. Régimen jurídico}

El Parlamento Europeo y el Consejo de la Unión Europea aprueban la Directiva 2003/98/CE, de 17 de noviembre de 2003, con el objeto de explotar el potencial de información del sector público y superar las barreras de un mercado europeo fragmentado estableciendo unos criterios homogéneos, asentados en condiciones equitativas, proporcionadas y no discriminatorias para el tratamiento de la información susceptible de ser reutilizada por personas físicas o jurídicas.

Con base en el art. 149.1.18 CE, las Cortes Generales en nuestro país aprueban la Ley $37 / 2007$, de 16 de noviembre, sobre reutilización de la información del sector público con carácter básico (disposición final primera), reformada por la Ley 18/2015, de 9 de julio.

(29) CERRILLO I MARTÍNEZ, A. "La información del sector público: del acceso a la reutilización». En CERRILLO I MARTÍNEZ, A. y GALÁN GALÁN, A. (Coords.) La reutilización de la información del sector público. Comares. Granada, 2006. Pág. 3.

(30) GARCÍA SAURA, P. J.: "La reutilización de recursos de la información en el sector turístico. Acceso por parte del entramado empresarial a la información administrativa y su posterior reutilización comercial», en Cuadernos de Turismo núm. 34. 2014. Págs. 102 y 105.

(31) Por ejemplo, la sustitución de la técnica autorizatoria por la declaración responsable a partir de la incorporación de la Directiva de Servicios a los ordenamientos internos. 
En el Estado la Ley 37/2007 es objeto de desarrollo por el Reglamento 1495/2011, de 24 de octubre, debiendo prestar atención a la Resolución de la Secretaría de Estado de Administraciones Públicas de 19 de febrero de 2013, por la que se aprueba la Norma Técnica de Interoperabilidad de reutilización de recursos de la información. En sede autonómica y a pesar del carácter básico de la Ley $37 / 2007$, resulta obligado citar la Ley del País Vasco 2/2016, de 7 de abril, de Instituciones Locales de Euskadi (32), así como el Acuerdo del Consejo de Gobierno de la Generalitat Valenciana de 5 de diciembre de 2014, por el que se aprueba la Agenda Digital de la Comunitat Valenciana 2014-2020. En materia de datos abiertos, este Acuerdo dedica la línea A.15 al Open data turístico, mientras que en lo referente a reutilización, a diferencia de otros sectores (educación, salud), este Acuerdo no dedica una línea de actuación específica para el turismo, si bien lo configura como un elemento transversal en diferentes ejes dentro de la participación activa.

La definición legal de la reutilización consiste en el uso de documentos que obran en poder de las Administraciones y organismos del sector público, por personas físicas o jurídicas, con fines comerciales o no comerciales, siempre que dicho uso no constituya una actividad administrativa pública (art. 3.1). El régimen administrativo de la reutilización comprende los formatos disponibles para la reutilización, la prohibición de derechos exclusivos, la aplicación de tarifas, las condiciones de reutilización, las licencias, el procedimiento de solicitud y el régimen sancionador. Por último no puede dejar de mencionarse que España ha obtenido la mayor puntuación por el Portal Europeo de Datos en el segundo Informe de Evaluación del Nivel de Madurez del Ecosistema de Datos Abiertos (33).

\section{III.2. Proyecto Aporta}

Como hemos adelantado y conscientes de la necesidad de reutilizar la información pública en cualquier sector de actividad, las distintas Administraciones Públicas disponen de portales en los que publican datos abiertos al objeto de que esa información sea compartida.

En particular la Administración General del Estado dispone desde 2009 de la Iniciativa Aporta, gestionada por la entidad pública empresarial Red. es, que inserta - entre otras informaciones - un catálogo de datos de

(32) Destina su art. 59 a la apertura de datos y el art. 60 a la reutilización de la información pública, remitiendo a la legislación básica las condiciones de su realización.

(33) Portal de Administración Electrónica. Consulta: 25 de noviembre de 2016. 
aquellas Administraciones que desean remitir determinada información por materias (34).

En el caso del turismo este catálogo alberga un total de 532 conjuntos de datos (35) clasificados por formato (csv, html, xls...), Administración publicadora (45 del Estado, 393 de Comunidades Autónomas y 94 de la Administración Local), y por materias (vacaciones, deporte, cultura, camping, turismo rural, albergues...).

La reutilización de datos con frecuencia da pie a la aparición de aplicaciones informáticas que combinan los datos existentes en redes digitales con determinadas necesidades. Un ejemplo es el mapa interactivo del diario El País, que se encuentra en (http://economia.elpais.com/ economia/2016/10/10/actualidad/1476090683_656197.html) (36) y que permite conocer el gasto diario de un turista por Comunidades autónomas. Esta aplicación - conocida como laboratorio de datos- hace acopio de la Encuesta de Gasto Turístico publicada por el Instituto Nacional de Estadística y la combina con la información periodística. Adicionalmente, a partir de los datos de la encuesta del INE, este laboratorio de datos también analiza la procedencia de los turistas por Comunidades autónomas.

\section{III.3. Ciudades inteligentes y datos abiertos}

La ciudad inteligente, conocida con el anglicismo de Smart city- no es otra cosa que la aplicación de medios técnicos a la gestión de servicios públicos locales al objeto de lograr una mayor eficiencia en la utilización de medios, espacios e infraestructuras de titularidad municipal.

En este sentido forman parte de la ciudad inteligente los sensores en los vehículos de transporte público para conocer dónde se encuentran y predecir el tiempo que tardan en llegar a una parada; un lector de fugas en la red de agua potable para maximizar este recurso... En definitiva se trata de objetos y sensores interconectados de manera permanente y automatizada que suministran una información en tiempo real. Todos estos datos, interconectados a su vez unos con otros, combinando distintas fuentes, arrojan a su vez otra información adicional tanto de la ciudad como muy especialmente de los ciudadanos.

(34) El portal español de datos abiertos (datos.gob.es) es parejo del europeo (data.europa.eu); $\sin$ embargo, el catálogo de este último no contiene, a diferencia del primero, un grupo temático del turismo, debiendo buscar tal clase de datos entre los asuntos de «Vida económica» o de «Intercambios económicos y comerciales".

(35) Fecha de consulta: 11 de diciembre de 2016.

(36) Fecha de consulta: 11 de diciembre de 2016. 
En este sentido los macro datos hacen posible una observación dinámica de la ciudad, de acuerdo con las teorías de urbanistas de los años setenta y ochenta del siglo $x x(37)$, pero también de las preferencias comerciales de sus habitantes, información que posee un enorme interés para los operadores económicos.

Un problema que no puede pasar desapercibido consiste en la multitud de actores que intervienen en las proyecciones de la ciudad inteligente. En efecto, si nuestro análisis se centra en la intervención administrativa en materia de turismo ante el reto del big data y el open data, en las distintas políticas públicas vinculadas directa o indirectamente al turismo interviene no sólo la Administración junto al prestador y al usuario del servicio turístico, sino también los prestadores de servicios de la sociedad de la información, que hacen acopio de unos datos de unos particulares que - con arreglo a la LOPD - no pueden ceder a terceros so pena de incurrir en una infracción (38).

Desde la perspectiva jurídica las transmisiones de datos en el marco de las ciudades inteligentes plantea la problemática del consentimiento. En efecto la LOPD hace descansar las garantías de la transmisión de datos en el consentimiento del afectado, que debe ser inequívoco (art. 6 LOPD). El acceso a los datos - públicos y privados - del ciudadano en un entorno de agentes públicos y privados con fines comerciales o no comerciales, en el contexto del denominado internet de las cosas, con el volumen, variedad y celeridad en la gestión de los mismos, no puede ampararse en el consentimiento del afectado(39).

Es cierto que este consentimiento no será preciso cuando los datos de carácter personal se recojan para el ejercicio de las funciones propias de las Administraciones Públicas en el ámbito de sus competencias; sin embargo no es menos cierto que (1) en ocasiones son agentes privados los que acceden a tales datos; (2) que - a pesar de todas las cautelas de anonimización de los datos - a día de hoy existen fórmulas para desanonimizar los datos encriptados, referenciando comportamientos y actitudes a individuos perfectamente identificados; y (3) que la comunicación de datos a un tercero sí requiere el consentimiento a no ser que la misma se encuentre autorizada por una ley (art. 11 LOPD).

(37) BARTHES, R.: Semiología y urbanismo. 1970. LYNCH, K.: La buena forma de la ciudad. 1981. GIOVENALE, F: Come leggere la città. 1977. FRIEDMAN, Y.: Hacia una arquitectura científica. Alianza editorial. Madrid, 1973.

(38) VALEROTORRIJOS, J. y ROBLES ALBERO, J. R.: "Open Smart cities: ¿de quién son los datos?", en AAVV.: Regulating Smart cities. Actas del XI Congreso Internacional Internet, Derecho y Política. UOC-Huygens Editorial. Barcelona, 2015. Pág. 17.

(39) FERNÁNDEZ BARBUDO, C.: «El papel de la Smart City en el concepto de privacidad», en AAVV.: Regulating Smart cities. Actas del XI Congreso Internacional Internet, Derecho y Política. UOC-Huygens Editorial. Barcelona, 2015. Pág. 98. 
Por otro lado, distinto del tratamiento de datos (art. 6) y de la comunicación de los mismos (art. 11) es el acceso a los datos por cuenta de terceros, cuya realización debe estar regulada en un contrato que debe constar por escrito o en alguna otra forma que permita acreditar su celebración y contenido, estableciéndose expresamente que el encargado del tratamiento únicamente tratará los datos conforme a las instrucciones del responsable del tratamiento, que no los aplicará o utilizará con fin distinto al que figure en dicho contrato, ni los comunicará, ni siquiera para su conservación, a otras personas (art. 12 LOPD).

Como puede apreciarse, la conclusión obligada es que el acceso y la reutilización de la información en el marco de la ciudad inteligente casa mal con un régimen jurídico centrado propiamente en los datos personales convencionales (la ideología, la religión o creencia, la salud...), para los que fue concebido la LOPD en 1999, y que la realidad de los hechos dista mucho de tener encaje en esa regulación.

A día de hoy el derecho positivo se viene construyendo sobre la base de la regulación comunitaria de los datos convencionales y de la técnica del consentimiento. No en vano el Grupo de Trabajo del Artículo 29 sobre Protección de Datos en su Dictamen 6/2013 recuerda que el acceso y la reutilización de datos personales que se hayan puesto a disposición del público siguen sujetos a la legislación sobre protección de datos. Por otro lado el Reglamento (UE) 2016/679, del Parlamento Europeo y del Consejo, de 27 de abril de 2016, relativo a la protección de las personas físicas en lo que respecta al tratamiento de datos personales y a la libre circulación de estos datos y por el que se deroga la Directiva 95/46/CE (Reglamento general de protección de datos), sigue apostando por este planteamiento y sus innovaciones en materia de control de los datos se centran fundamentalmente en el derecho al olvido y el derecho a la portabilidad.

A nuestro entender el principio de Administración abierta debe ser repensado (40), valorando las indudables ventajas del acceso a los datos y su reutilización, pero siendo conscientes que resulta inviable someterlo al consentimiento del afectado. Conviene replantear radicalmente el modelo de transferencia de datos en un nuevo entorno, que es el propio de los macro datos.

Una fórmula de control administrativo al objeto de evitar abusos podría ser, en el contexto de la actividad de policía administrativa, recoger en una norma la obligación del operador de detener cualquier transmisión o utilización de datos en las que su titular manifieste su voluntad contraria, seguido de un tipo infractor con una sanción ejemplar.

(40) MASSENO, M. D.: "Da Proteçao de dados em tempos de "Big Data». Que exigências para as Administraçoes Públicas?»,conferencia pronunciada en el Congreso Proteçao e Segurança de Dados. Um imperativo para os Serviços Públicos. Praia, 15 de diciembre de 2015. 


\section{Conclusiones}

El análisis de la realidad presente anuncia un nuevo paradigma de la relación jurídica en materia de turismo basado en la innovación tecnológica y la apertura de datos (41).

Las posibilidades de los macro datos y los datos abiertos dan lugar a una nueva categoría de datos muy distintos a los convencionales y para los que no pensaba el legislador a la hora de elaborar el régimen jurídico vigente de protección de datos.

Por razones obvias las ventajas de la innovación tecnológica en general y en materia de turismo en particular, no pueden eliminar las garantías de los titulares de los datos, aprehendidos para fines comerciales sin su consentimiento y al margen de principio de proporcionalidad. El usuario que consulta el precio de un alojamiento o un transporte turísticos no está consintiendo que este dato sea gestionado para ofertarse un precio cada vez superior en una consulta posterior desde un mismo terminal informático o dispositivo electrónico.

La conclusión obligada del análisis que precede es que los instrumentos normativos vigentes han quedado obsoletos y desde luego muy alejados de la realidad social que deben regular. Peor que eso, ya nacen obsoletos por cuanto resulta materialmente imposible residenciar los derechos del titular de datos en el consentimiento. Los macro datos irrumpen con tal fuerza arrolladora en la transmisión de información que carece de efectividad tratar de limitarla por el consentimiento inequívoco.

Urge diseñar un modelo integrador de gestión de datos, que tenga en cuenta la combinación e interconexión de datos de múltiples y variadas fuentes, pero muy especialmente la intervención de múltiples sujetos, y sin olvidar la imprescindible interoperabilidad (42).

En los últimos años el derecho administrativo apunta a la colaboración público-privada, como consecuencia del agotamiento de los recursos públicos para gestionar los asuntos considerados de interés general: la crisis del concepto de servicio público (que permite que sujetos privados puedan prestar servicios públicos)(43), el contrato de concesión de obra pública tipificado en 2003 al superar la fórmula de los contratos mixtos (que evita que la Administración deba de financiar la construcción de una

(41) VALEROTORRIJOS, J.: «De la digitalización a la innovación tecnológica: valoración jurídica del proceso de modernización de las Administraciones Públicas españolas en la última década (20042014)", en IDP Revista de Internet, Derecho y Política núm. 19. Octubre, 2014.Pág. 125.

(42) GAMERO CASADO, E.: «Interoperabilidad y Administración electrónica: conéctense, por favor», en Revista de Administración Pública núm. 179. Mayo-agosto 2009. Págs. 291 a 332.

(43) GARRIDO FALLA, F: "El concepto de servicio público en derecho español», en Revista de Administración Pública núm. 135. Septiembre-diciembre 1994. Págs. 7 a 36. 
obra pública) (44), las fórmulas de colaboración contractual público-privada a partir de la Ley 30/2007, de Contratos del Sector Público (45), los mecanismos de autorregulación de determinados sectores como las denominaciones de origen (46)...

Siguiendo esta tendencia, deviene imprescindible en materia de macro datos y datos abiertos, adaptar el régimen jurídico de la protección de datos a una realidad que, independientemente de la vigencia de la LOPD, sigue su camino al margen de cualquier consideración legal. Esta adaptación pasa por involucrar al sector privado tanto en el modelo de gestión de los datos como en su control.

Este nuevo modelo de gestión de datos se convierte en un elemento estratégico por cuanto su importancia no se reduce exclusivamente a garantizar los derechos del titular de los datos (cualquier ciudadano), sino que la gestión del acceso influye en la reutilización, y viceversa, esta última hace posible el primero. Big data y open data forman así un itinerario de ida y vuelta sin fin.

\section{Bibliografía}

AAVV.: Big data. Retos y oportunidades para el turismo. Instituto Valenciano de Tecnologías Turísticas. Valencia, 2015.

ABERASTURI GORRIÑO, U.: "Movimiento internacional de datos. Especial referencia a la transferencia internacional de datos sanitarios", en Revista de Administración Pública núm. 186. Madrid, septiembre-diciembre 2011. Págs. 329 a 369.

ALFONSO SÁNCHEZ, R. y BURILLO SÁCNHEZ, F. J.: «La economía llamada colaborativa». En ALFONSO SÁNCHEZ, R. VALEROTORRIJOS, J. (Directores): Retos jurídicos de la economía colaborativa en el contexto digital.The Global Collection. AranzadiThomson Reuters. 2017.

BARCELÓ, R. y PÉREZ ASINARI, M. V.: «Transferencia internacional de datos personales", en MARTíNEZ MARTÍNEZ, R. (Coord.), Protección de Datos. Comentarios al Reglamento al Reglamento de desarrollo de la LOPD. Tirant lo Blanch. Valencia, 2009.

BARTHES, R.: Semiología y urbanismo. 1970.

(44) Vid. MENÉNDEZ MENÉNDEZ, A. (Dir.): Comentarios a la nueva Ley 13/2003, de 23 de mayo, reguladora del contrato de concesión de obra pública. Thomson - Civitas. Madrid, 2003.

(45) GONZÁLEZ GARCíA, J. V.: "Contrato de colaboración público-privada», en Revista de Administración Pública núm. 170. Mayo-agosto 2006. Págs. 7 a 39.

(46) BAUZÁ MARTORELL, F. J.: "Jurisdicción y autorregulación. Los consejos reguladores de las denominaciones de origen", en SORIANO GARCÍA, J. E. (Dir.): Por el Derecho y la Libertad. Libro homenaje al Profesor Juan Alfonso Santamaría Pastor. Vol. II. lustel. Madrid, 2014. Págs. 1409 a 1438. 
BAUZÁ MARTORELL, F. J.: «Replanteamiento de la intervención administrativa en materia de turismo ante las nuevas tecnologías", en Actualidad Administrativa núm. 3. Marzo 2016. Págs. 61 a 75.

- «Transformaciones del derecho público del turismo con ocasión de las nuevas tecnologías", en MARTíNEZ NADAL, A. (Coord.): Turismo y nuevas tecnologías. Thomson Reuters - Aranzadi. Cizur Menor, 2016. Págs. 127 a 156.

- "Habeas denuncia. Identidad del denunciante en el procedimiento sancionador", en Revista General de Derecho Administrativo núm. 40. lustel. Octubre de 2015.

- "Jurisdicción y autorregulación. Los consejos reguladores de las denominaciones de origen", en SORIANO GARCÍA, J. E. (Dir.): Por el Derecho y la Libertad. Libro homenaje al Profesor Juan Alfonso Santamaría Pastor. Vol. II. lustel. Madrid, 2014. Págs. 1409 a 1438.

- «Hacia una legislación básica en materia de turismo. A propósito de las centrales electrónicas de reservas turísticas", en Diario La Ley. 27 de mayo de 2014.

- «Incidencia de la Directiva de Servicios en la legislación turística. Estudio autonómico comparado». En JIMÉNEZ CABALLERO, J. L. y DE FUENTES RUIZ, P. (Coords.): Turismo y desarrollo económico. Actas de las IV Jornadas de Investigación en Turismo. Facultad de Turismo y Finanzas de la Universidad de Sevilla. 2011. Págs. 339 a 355.

BUISÁN GARCÍA, N.: "Movimiento internacional de datos», en LESMES SERRANO, C. (Coord.): La Ley de Protección de Datos. Análisis y Comentario de su Jurisprudencia. Lex Nova. Valladolid, 2008.

CANNATACI, J. A.: Report of the Special Rapporteur on the right to privacy. Human Rigths Council. United Nations. 2016.

CERRILLO I MARTÍNEZ, A.: "La información del sector público: del acceso a la reutilización", en CERRILLO I MARTÍNEZ, A. y GALÁN GALÁN, A. (Coords.): La reutilización de la información del sector público. Comares. Granada, 2006.

COTINO HUESO, L.: «EI derecho fundamental de acceso a la información, la transparencia de los poderes públicos y el Gobierno Abierto. Retos y oportunidades", en VALEROTORRIJOS, J. y FERNÁNDEZ SALMERÓN, M. (Coords.): Régimen jurídico de la transparencia del sector público. Thomson Reuters - Aranzadi. Cizur Menor, 2014. Págs. 37 a 71.

FERNÁNDEZ BARBUDO, C.: «El papel de la Smart City en el concepto de privacidad", en AAVV. Regulating Smart cities. Actas del XI Congreso Internacional Internet, Derecho y Política. UOC-Huygens Editorial. Barcelona, 2015. Págs. 93 a 112.

FERNÁNDEZ SALMERÓN, M. y VALEROTORRIJOS, J.: "Las infracciones de las Administraciones Públicas», en TRONCOSO, A. (Dir.) Comentarios a 
la Ley Orgánica de Protección de Datos de Carácter Personal. Thomson Reuters - Aranzadi. Cizur Menor, 2010.

FERNÁNDEZ RODRÍGUEZ, C.: Derecho administrativo del turismo. Séptima edición. Marcial Pons. Madrid, 2016.

FRIEDMAN, Y.: Hacia una arquitectura científica. Alianza editorial. Madrid, 1973.

GAMERO CASADO, E.: "Interoperabilidad y Administración electrónica: conéctense, por favor», en Revista de Administración Pública núm. 179. Mayo-agosto 2009. Págs. 291 a 332.

GARCÍA SAURA, P. J.: "La reutilización de la información en el sector turístico. Acceso por parte del entramado empresarial a la información administrativa y su posterior reutilización comercial», en Cuadernos de Turismo núm. 34. 2014. Págs. 89 a 113.

GARRIDO FALLA, F:: «El concepto de servicio público en derecho español», en Revista de Administración Pública núm. 135. Septiembre-diciembre 1994. Págs. 7 a 36.

GIOVENALE, F.: Come leggere la città. 1977.

GONZÁLEZ GARCÍA, J. V.: "Contrato de colaboración público-privada», en Revista de Administración Pública núm. 170. Mayo-agosto 2006. Págs. 7 a 39.

GUICHOT REINA, E.: "El sentido, el contexto y la tramitación de la Ley de transparencia, acceso a la información pública y buen gobierno", en GUICHOT REINA, E. (Coord.): Transparencia, acceso a la información pública y buen gobierno.Tecnos. Madrid, 2014. Págs. 17 a 34.

LYNCH, K.: La buena forma de la ciudad. 1981.

MARTÍNEZ MARTÍNEZ, R.: "De la opacidad a la casa de cristal. El conflicto entre privacidad y transparencia», en VALEROTORRIJOS, J. y FERNÁNDEZ SALMERÓN, M. (Coords.): Régimen jurídico de la transparencia del sector público. Del derecho de acceso a la reutilización de la información. Thomson Reuters Aranzadi. Cizur Menor, 2015. Págs. 241 a 280.

MASSENO, M. D.: «Personal data circulation from the EU to USA and now what for the American Tourism Industry with business in Europe? ", conferencia pronunciada en la 23rd International Tourism Safety Conference. Las Vegas, Nevada, del 10 al 13 de abril de 2016.

- "Da Proteçao de dados em tempos de "Big Data». Que exigências para as AdministraÇoes Públicas?», Conferencia pronunciada en el Congreso Proteçao e Segurança de Dados. Um imperativo para os Serviços Públicos. Praia, 15 de diciembre de 2015.

MENÉNDEZ MENÉNDEZ, A. (Dir.): Comentarios a la nueva Ley 13/2003, de 23 de mayo, reguladora del contrato de concesión de obra pública. Thomson - Civitas. Madrid, 2003.

MONTERO PASCUAL, J. J.: La regulación de la economía colaborativa. En MONTERO PASCUAL, J. J. (Director) La regulación de la economía cola- 
borativa. Airbnb, BlaBlaCar, Uber y otras plataformas. Tirant lo Blanch. Valencia, 2017.

PÉREZ MONGUIÓ, J. M. y FERNÁNDEZ RAMOS, S. La Ley de Transparencia, acceso a la información pública y buen gobierno. AranzadiThomson Reuters. Cizur Menor, 2014.

RAMALLO MIÑÁN, E. P.: Manual básico del derecho turístico. Tecnos. Madrid, 2013.

REBOLLO PUIG, M.: "La actividad inspectora», en DÍEZ SÁNCHEZ, J. J. (Coord.): La función inspectora. Actas del VIII Congreso de la Asociación Española de profesores de Derecho Administrativo. Alicante, 8 y 9 de febrero de 2013. Págs. 55 a 116.

VALERO TORRIJOS, J.: «De la digitalización a la innovación tecnológica: valoración jurídica del proceso de modernización de las Administraciones Públicas españolas en la última década (2004-2014)», en IDP Revista de Internet, Derecho y Política núm. 19. Octubre, 2014.Pág.

- «El big data en las Administraciones Públicas: el difícil equilibrio entre eficacia de la actividad administrativa y garantía de los derechos de los ciudadanos", en AAVV.: Big data. Retos y oportunidades. Actas del IX Congreso Internacional Internet, Derecho y Política. Universitat Oberta de Catalunya. Barcelona, 25 y 26 de junio de 2013. Págs. 127 a 137.

VALERO TORRIJOS, J. y ROBLES ALBERO, J. R.: «Open Smart cities: ¿de quién son los datos?", en AAVV.: Regulating Smart cities. Actas del XI Congreso Internacional Internet, Derecho y Política. UOC-Huygens Editorial. Barcelona, 2015. Págs. 15 a 27.

Trabajo recibido el 20 de febrero de 2017

Aceptado por el Consejo de Redacción el 26 de mayo de 2017 
LABURPENA: Turismoaren arloan, harreman juridikoaren paradigma berri baten aurrean gaude, zeina berrikuntza teknologikoan eta datuak irekitzean oinarritzen den. Makro-datuak eta datu irekiak izateko aukerak datu-kategoria berri bat ekarri dute, ohiko datuekin alderatuta ezberdina. Legegileak ez zuen datu horietan pentsatu datuak babesteko arloan indarrean dagoen araubide juridikoa egiteko orduan. Indarrean dauden tresna arautzaileak zaharkituta geratu dira, eta, zalantzarik gabe, erregulatu behar duten gizarte-errealitatetik oso urrun.

Artikulu honetan, indarrean dagoen araudia aztertuko da. Aldi berean, ordea, araudi hori aldatzeko modua iradokiko da, errealitate berrira egokitu dadin.

GAKO HITZAK: Makro-datuak. Datu irekiak. Sarbidea. Berrerabiltzea. Informazio publikoa. Turismo-administrazioa.

RESUMEN: Asistimos a un nuevo paradigma de la relación jurídica en materia de turismo basado en la innovación tecnológica y la apertura de datos. Las posibilidades de los macro datos y los datos abiertos dan lugar a una nueva categoría de datos muy distintos a los convencionales y para los que no pensaba el legislador a la hora de elaborar el régimen jurídico vigente de protección de datos. Los instrumentos normativos vigentes han quedado obsoletos y desde luego muy alejados de la realidad social que deben regular.

En este artículo se aborda un análisis de la normativa vigente, al tiempo que se sugiere su reforma y adaptación a la nueva realidad.

PALABRAS CLAVE: Macro datos. Datos abiertos. Acceso. Reutilización. Información pública. Administración turística.

ABSTRACT: A new paradigm for the legal relationship regarding tourism based in technological innovation and opening of data is noticed. The possibilities of macro data and open data give rise to a new data category which are very different from conventional data and that were not kept in mind by the legislator when elaborating the current legal regime for data protection. The normative tools in force have become obsolete and they are certainly rather far away from the social reality they are supposed to regulate.

KEYWORDS: Macro data. Open data. Access. Re-use. Public information. Tourism administration. 